\title{
Expression of the Clonostachys rosea lactonohydrolase gene by Lactobacillus reuteri to increase its zearalenone-removing ability
}

\author{
Wen-Chun Yang ${ }^{1 \dagger}$, Tsui-Chun Hsu ${ }^{2 \dagger}$, Kuan-Chen Cheng $^{1,3,4^{*}}$ and Je-Ruei Liu $23,55^{*}$
}

\begin{abstract}
Background: Mycotoxins are secondary metabolites produced by filamentous fungi that can contaminate agricultural crops in the field as well as during harvest, transportation, processing, or storage. Zearalenone (ZEN), a nonsteroidal estrogenic mycotoxin, produced by Fusarium species, has been shown to be associated with reproductive disorders in farm animals and to a lesser extent in hyperoestrogenic syndromes in humans. Thus, the decontamination of ZEN in foods and feeds is an important issue.

Results: In this study, the gene encoding ZHD101, a ZEN-degrading enzyme produced by Clonostachys rosea IFO 7063, was cloned into an Escherichia coli-Lactobacillus shuttle vector, pNZ3004, and the resultant plasmid pNZ-zhd101 was then introduced via electroporation into Lactobacillus reuteri Pg4, a probiotic strain isolated from the gastrointestinal tract of broilers. The transformed strain L. reuteri pNZ-zhd101 acquired the capacity to degrade ZEN. In addition, the production of recombinant ZHD101 did not affect cell growth, acid and bile salt tolerance, and had only a minor effect on the adhesion ability of L. reuteri pNZ-zhd101.
\end{abstract}

Conclusions: To the best of our knowledge, this is the first report of successful expression of a ZEN-degrading enzyme by intestinal lactobacilli.

Keywords: Zearalenone, Lactonohydrolase, Lactobacillus reuteri, Probiotics

\section{Background}

Mycotoxins are secondary metabolites produced by filamentous fungi that can contaminate agricultural crops in the field as well as during harvest, transportation, processing, or storage. The Food and Agriculture Organization (FAO) estimates that $25 \%$ of the world's crop-based agricultural commodities are contaminated with mycotoxins, resulting in an estimated global loss of foodstuffs in the range of 1000 million tonnes annually [1]. Zearalenone (ZEN), a non-steroidal estrogenic mycotoxin produced by Fusarium fungi, is one of the most commonly found mycotoxins in food and feed [2]. ZEN can activate estrogenic receptors, resulting in reproductive disorders

\footnotetext{
*Correspondence: kccheng@ntu.edu.tw; jrliu@ntu.edu.tw

${ }^{\dagger}$ Wen-Chun Yang and Tsui-Chun Hsu contributed equally to this work

${ }^{3}$ Institute of Biotechnology, National Taiwan University, No. 1, Sec. 4,

Roosevelt Rd., Taipei 10617, Taiwan

Full list of author information is available at the end of the article
}

in farm animals and occasionally in hyperoestrogenic syndrome in humans [3]. Thus ZEN not only causes significant economic losses due to the lower efficacy of livestock production but also poses a health risk to humans who consume ZEN-contaminated foods [4]. The prevention of ZEN contamination in food and feed is an ideal solution for reducing the health rick of ZEN. However, it is considered that ZEN contamination cannot be avoided by the current agricultural practice [5]. Therefore, detoxification of ZEN in foods and feeds is another option for agricultural commodities already contaminated with ZEN. The strategies for decontamination of ZEN in foods and feeds include chemical methods such as exposure of ZEN-containing foods to ozone or hydrogen peroxide; physical methods such as extrusion processing; and biological methods such as using biotransforming agents to degrade ZEN into non-toxic metabolites or using adsorbing agents to decrease its bioavailability [3]. Among 
these ZEN detoxification methods, biological methods are preferable because they provides the opportunity for removal of mycotoxins under mild conditions without using harmful chemicals or causing significant losses in nutritive value and palatability of decontaminated food and feed [6, 7]. ZHD101, a lactonohydrolase produced by the fungal species Clonostachys rosea, converts ZEN into 1-(3,5-dihydroxy-phenyl)-10-hydroxy-1-undecen6-one, which is a markedly less toxic product [8]. In previous studies, ZHD101 has been shown to be successfully expressed by Escherichia coli, Saccharomyces cerevisiae, and rice plants, and the recombinant ZHD101 produced by these genetically modified organisms effectively degraded ZEN $[9,10]$.

Probiotics have long been used as feed additives because of their abilities to normalize gut microbiota, boost the immune system, prevent diarrhea, and improve feed conversion efficiency [11, 12]. Although probiotics exert a number of beneficial effects, it has been speculated that their properties could be further improved through genetic modification [13, 14]. Examples of such genetically modified probiotics include those that produce antigens, enzymes, and cytokines for immune intervention $[15,16]$. Lactobacillus reuteri is one of the potential probiotics that frequently occurs in the intestinal microflora of animals [17]. L. reuteri Pg4 was originally isolated from the gastrointestinal tract of a healthy broiler and has been shown to be capable of tolerating acid and bile salts, inhibiting pathogen growth, and adhering to mucin and mucus [18]. Moreover, L. reuteri $\mathrm{Pg} 4$ has been used to heterologously express some fibrolytic enzymes including $\beta$-glucanase, xylanase, and cellulase. Recombinant $L$. reuteri Pg4 strains have been demonstrated to acquire the capacity to break down fibers without losing their probiotic properties $[14,19,20]$.

In the present study, we describe the heterologous expression of the $z h d 101$ gene derived from C. rosea in $L$. reuteri Pg4. We also examined the heterologous enzyme production, acid and bile salt tolerance, as well as the adherence capability of the transformed $L$. reuteri strain.

\section{Results}

\section{Heterologous expression of ZHD101 in recombinant $L$.} reuteri Pg4

For heterologous expression of ZHD101 in L. reuteri Pg4, the DNA fragments encoding C. rosea ZHD101 were inserted into the Lactobacillus expression vector pNZ3004, resulting in the plasmid pNZ-zhd101 (Fig. 1). The plasmids pZN3004 and pNZ-zhd101 were then introduced via electroporation into L. reuteri Pg4. The transformation efficiency of pNZ-zhd101 was similar to that of pNZ3004 $\left[(8-10) \times 10^{2}\right.$ transformants $/ \mu \mathrm{g}$ of DNA]. The presence of the zhd101 gene in L. reuteri
pNZ-zhd101 was demonstrated by direct colony PCR (results not shown). The transcription of ZHD101 in $L$. reuteri pNZ-zhd101 was further confirmed by reverse transcription PCR (RT-PCR) analysis. A 0.8-kb fragment, which is consistent in size with zhd101, was amplified by RT-PCR from total RNA extracted from L. reuteri pNZzhd101 cells but was not detected from RNA extracted from L. reuteri Pg4 or L. reuteri pNZ3004 cells, indicating that ZHD101 RNA was successfully expressed by $L$. reuteri pNZ-zhd101 (Fig. 2a).

The translation of ZHD101 in L. reuteri Pg4 and its transformed strains was confirmed by western blot analysis using ZHD101-specific polyclonal antibodies. As shown in Fig. 2b, the antibodies clearly labeled a band at the expected size for ZHD101 (about $30 \mathrm{kDa}$ ) in the intracellular extract of $L$. reuteri pNZ-zhd101 cells, but not in extracts of L. reuteri Pg4 and L. reuteri pNZ3004 cells, indicating that ZHD101 could be heterologously expressed by L. reuteri pNZ-zhd101.

\section{Growth characteristics and ZEN-degrading activity of $L$. reuteri pNZ-zhd101}

To determine the ZEN-degrading activity, L. reuteri Pg4, L. reuteri pNZ3004, and L. reuteri pNZ-zhd101 were respectively inoculated into de Man, Rogosa and Sharpe (MRS) broth containing $4.5 \mathrm{mg} / \mathrm{L}$ of ZEN and allowed to ferment for $14 \mathrm{~h}$. The $\mathrm{pH}$ of the broth was maintained at 7.0 during the fermentation. As shown in Fig. 3, L. reuteri $\mathrm{Pg} 4$ reached the stationary phase after $8 \mathrm{~h}$ of fermentation, with an $\mathrm{OD}_{600}$ of $1.83 \pm 0.06$ and bacterial counts of $6.65 \pm 1.21 \times 10^{9} \mathrm{CFU} / \mathrm{mL}$. L. reuteri pNZ3004 also reached the stationary phase after $8 \mathrm{~h}$ of fermentation; however, it had a lower $\mathrm{OD}_{600}$ than $L$. reuteri Pg4 during the exponential phase. L. reuteri pNZ-zhd101 reached the stationary phase after $10 \mathrm{~h}$ of fermentation and had a lower $\mathrm{OD}_{600}$ than the other two strains during the exponential phase. Although L. reuteri pNZ-zhd101 took longer to reach the stationary phase, the cell counts of $L$. reuteri $\mathrm{pNZ}$-zhd101did not differ significantly from those of $L$. reuteri $\mathrm{Pg} 4$ and $L$. reuteri pNZ3004 in the stationary phase.

The ZEN-degrading activity of $L$. reuteri pNZ-zhd101 was evaluated by determining the ZEN concentrations in MRS broth containing ZEN during the fermentation in a fermentor. As a reference and to compare ZEN-degrading activities, $L$. reuteri $\mathrm{Pg} 4$ and $L$. reuteri pNZ3004 were cultured and investigated using the same procedure. As shown in Fig. 3, L. reuteri pNZ-zhd101 displayed characteristic degradation effects on ZEN. After incubation of $L$. reuteri pNZ-zhd101 in the MRS broth containing $4.5 \mathrm{mg} / \mathrm{L}$ of ZEN for $14 \mathrm{~h}$, the ZEN concentration decreased to $0.03 \pm 0.01 \mathrm{mg} / \mathrm{L}$, while that observed for L. reuteri $\mathrm{Pg} 4$ and $L$. reuteri pNZ3004 was $4.28 \pm 0.10$ 


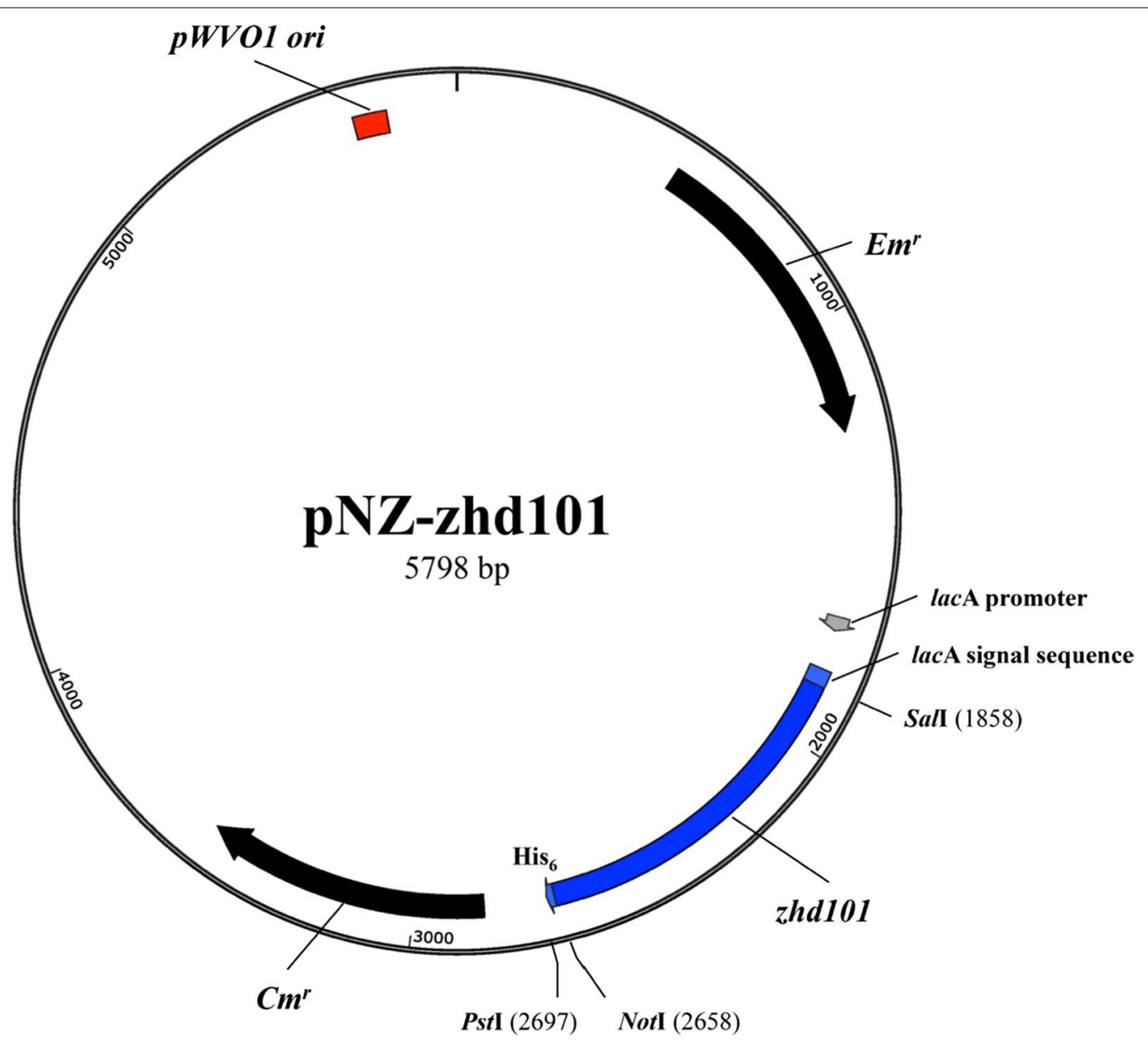

Fig. 1 Lactobacillus expression plasmid harboring the Clonostachys rosea zearalenone hydrolase gene zhd101

and $4.21 \pm 0.02 \mathrm{mg} / \mathrm{L}$, respectively (Fig. 3). These results demonstrated that the ZEN-degrading activity of $L$. reuteri pNZ-zhd101 was significantly greater than the activities of $L$. reuteri Pg4 and L. reuteri pNZ3004, indicating that ZHD101 was functionally expressed by $L$. reuteri pNZ-zhd101.

\section{Acid and bile salt tolerance of $L$. reuteri pNZ-zhd101}

The acid tolerance of L. reuteri Pg4, L. reuteri pNZ3004, and $L$. reuteri pNZ-zhd101 was evaluated by culturing the bacterial cells at $\mathrm{pH} 3.0$ and at $37{ }^{\circ} \mathrm{C}$ for $4 \mathrm{~h}$, while the bile-salt tolerance of the $L$. reuteri strains was determined by culturing the bacterial cells in MRS broth containing $0.5 \%$ ox gall at $37{ }^{\circ} \mathrm{C}$ for $24 \mathrm{~h}$. As shown in Fig. 4 , all $L$. reuteri strains survived after an incubation period of $4 \mathrm{~h}$ at $\mathrm{pH} 3.0$ (Fig. $4 \mathrm{a}$ ) and after incubation for $24 \mathrm{~h}$ in MRS broth containing $0.5 \%$ ox gall (Fig. $4 \mathrm{~b}$ ). The bacterial counts of L. reuteri pNZ3004 and L. reuteri pNZ-zhd101 did not differ significantly from those of L. reuteri Pg4 in the acid condition or in the presence of bile salts. These results indicated that all of the L. reuteri Pg4 strains have the ability to tolerate acid and bile salts.

\section{Adhesion ability of $L$. reuteri pNZ-zhd101}

The adhesion abilities of the $L$. reuteri strains were determined by culturing the hexidium iodide (HI)-stained L. reuteri cells with Caco- 2 cells. The Caco- 2 cells had weak autofluorescence as shown in the histogram plotted in Fig. 5a. After incubating Caco-2 cells with each HIstained $L$. reuteri strains for $2 \mathrm{~h}$, there was a shift along the fluorescence axis relative to the autofluorescence expressed by Caco- 2 cells alone (Fig. $5 b-d$ ), indicating adhesion of bacterial cells to the Caco- 2 cells. The mean fluorescence intensity of Caco-2 cells incubated with HI-stained L. reuteri Pg4 was significantly greater than that of Caco- 2 cells alone $(15.53 \pm 1.50$ vs. $0.32 \pm 0.09)$ $(p<0.05)$, indicating that L. reuteri Pg4 efficiently adhered to Caco-2 cells (Fig. 5b). The mean fluorescence intensity of Caco- 2 cells incubated with L. reuteri pNZzhd101 (10.13 \pm 1.41$)$ was also significantly greater than 

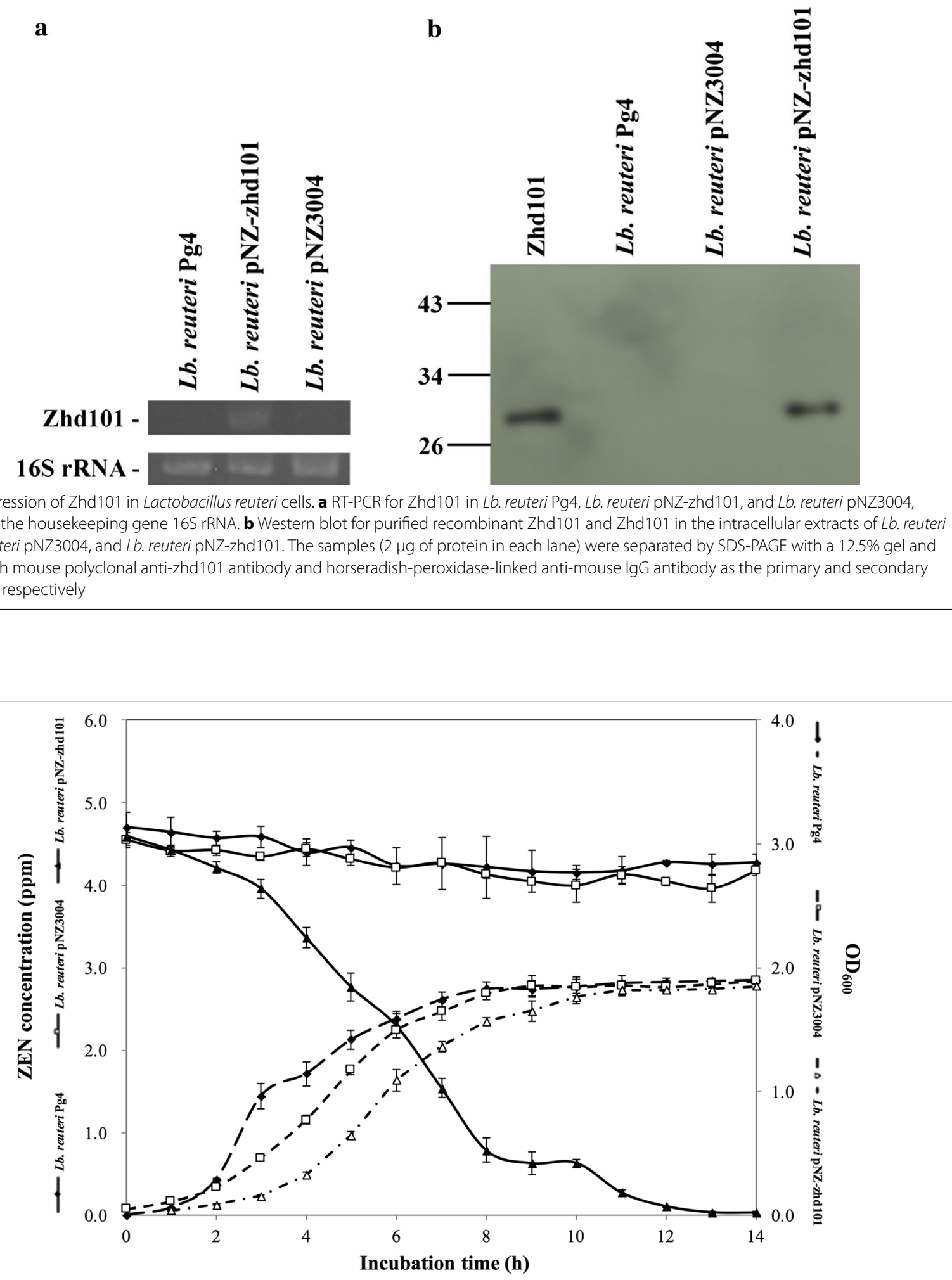

Fig. 3 Changes in ZEN concentrations of MRS media containing ZEN (4.5 mg/L) incubated with L. reuteri Pg4 or L. reuteri pNZ-zhd101. The pH values of culture media were adjusted to $\mathrm{pH} 7.0$ by adding $0.1 \mathrm{~N} \mathrm{NaOH}$ every hour 

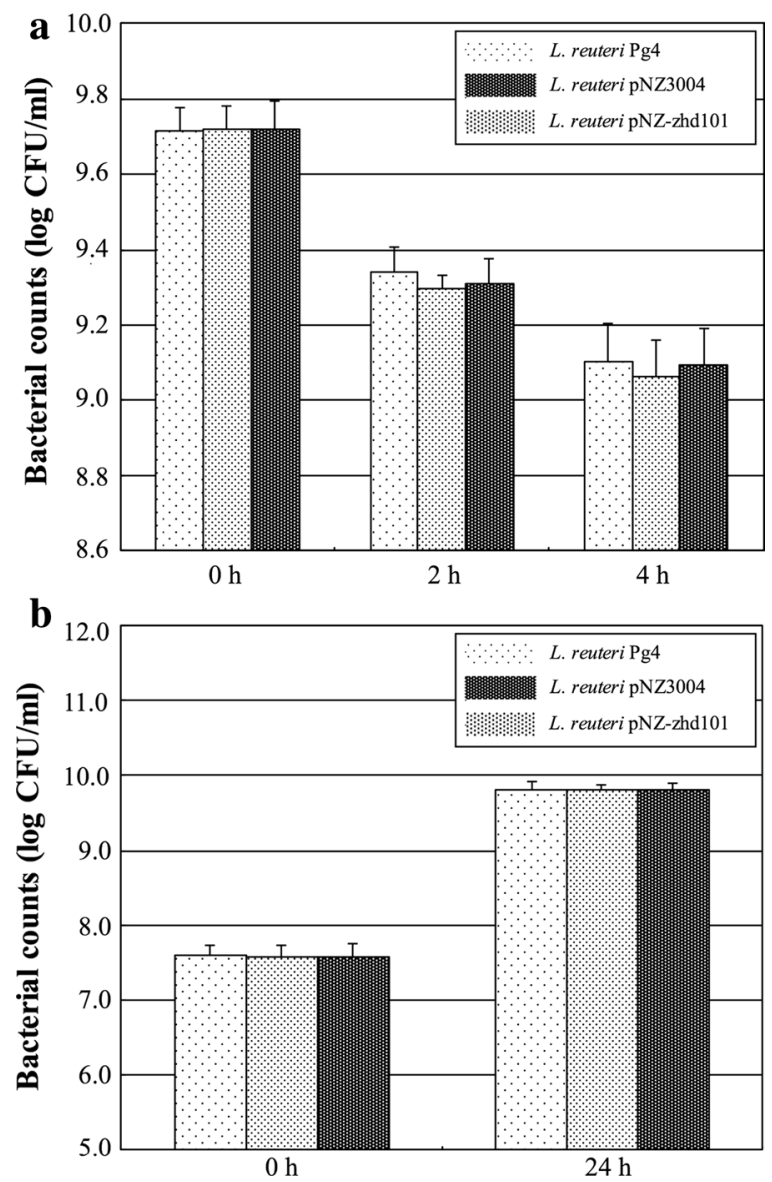

Fig. 4 Survival of L. reuteri Pg4, L. reuteri pNZ3004 and L. reuteri pNZzhd101 after incubation at pH 3.0 (a) or in the presence of $0.5 \%$ ox gall (b). The bars represent standard errors of the means calculated from three independent experiments performed in triplicate

that of Caco- 2 cells alone $(p<0.05)$ but was significantly lower than that of Caco-2 cells incubated with $L$. reuteri Pg4, indicating that constitutive expression of the recombinant ZHD101 protein in L. reuteri pNZ-zhd101 resulted in a decrease in adhesion ability to Caco- 2 cells. However, L. reuteri pNZ-zhd101 retained its adhesion ability at a certain level.

\section{Discussion}

Probiotics exert beneficial effects on animal performance by normalizing gastrointestinal microflora and offer great potential as feed additives to replace antibiotics [21]. Genetic modification could increase the effectiveness and usefulness of some probiotics. For example, certain probiotics could be modified to express and secrete of specific heterologous enzymes [16]. Probiotics that secrete specific enzymes can provide additional beneficial effects by delivering the enzymes directly to the target site, typically the intestine, where most of the feed digestion and nutrient absorption occurs. Other benefits include the reduced cost of enzyme supplementation because the genes for these enzyme genes could be replicated and expressed by the probiotics within the digestive tract [20]. In previous studies, we induced $L$. reuteri $\mathrm{Pg} 4$ to express fibrolytic enzymes and found that the transformed $L$. reuteri strains acquired the capacity to break down plant fibers, resulting in body-weight gain and improved feedconversion efficiency in broilers [14, 19, 22, 23]. In the present study, the C. rosea zhd101 gene was introduced into L. reuteri Pg4 and the transformed strain L. reuteri pNZ-zhd101 successfully expressed ZHD101 and acquired the capacity to degrade ZEN. To the best of our knowledge, this is the first report of successful expression of a ZEN-degrading enzyme by intestinal lactobacilli.

After incubating the three $L$. reuteri strains in MRS broth containing $4.5 \mathrm{mg} / \mathrm{L}$ of ZEN for $14 \mathrm{~h}$, we found that the concentration of ZEN in L. reuteri pNZ-zhd101-containing broth decreased by $99.3 \%$. In contrast, the ZEN concentration in broth containing $L$. reuteri $\mathrm{Pg} 4$ had only decreased by $9.1 \%$ and that in broth containing $L$. reuteri pNZ3004 only decreased by $7.5 \%$ (Fig. 3). Although the reduction in ZEN concentration by $L$. reuteri $\operatorname{Pg} 4$ and $L$. reuteri $\mathrm{pNZ} 3004$ was significantly lower than the reduction by $L$. reuteri pNZ-zhd101, the result shows that $L$. reuteri Pg4 and L. reuteri $\mathrm{pNZ3004}$ have ZEN-removing abilities. Previous studies have shown that some probiotics such as Bacillus, Bifidobacterium, Lactococcus, and Lactobacillus strains have mycotoxin-adsorption abilities [24, 25]. The ZEN-adsorption ability of L. rhamnosus was attributed to its polysaccharide components of the cell wall [26] while the fumonisin B1-adsorption ability of $B$. subtilis was attributed to its peptidoglycans [27]. In this study, L. reuteri $\mathrm{Pg} 4$ and $L$. reuteri pNZ3004 only slightly decreased the concentration of ZEN in culture media, suggesting that $L$. reuteri $\mathrm{Pg} 4$ may possess ZEN-adsorption ability. Future research will be conducted to demonstrate the ZEN-adsorption ability of L. reuteri Pg4 and confirm which components contribute to the adsorption of ZEN.

Takahashi-Ando et al. found that recombinant ZHD101 obtained from an E. coli expression system was irreversibly inactivated at $\mathrm{pH}$ values below 4.5 [9]. For this reason, we maintained the $\mathrm{pH}$ value of the culture medium for $L$. reuteri $\mathrm{pNZ}$-zhd101 at 7.0 during the fermentation process and found that L. reuteri pNZ-zhd101 could effectively remove ZEN under this culture condition (Fig. 3). These results indicated that the recombinant ZHD101 produced by $L$. reuteri pNZ-zhd101 is in an active form at $\mathrm{pH}$ 7.0. The mean $\mathrm{pH}$ values in small intestine, caecum, and colon of swine are 6.5, 6.1, and 6.5, respectively [28], while the mean $\mathrm{pH}$ values in crop, small intestine, caecum, and colon of chickens are 6.1, 6.4, 6.4, and 6.6, 

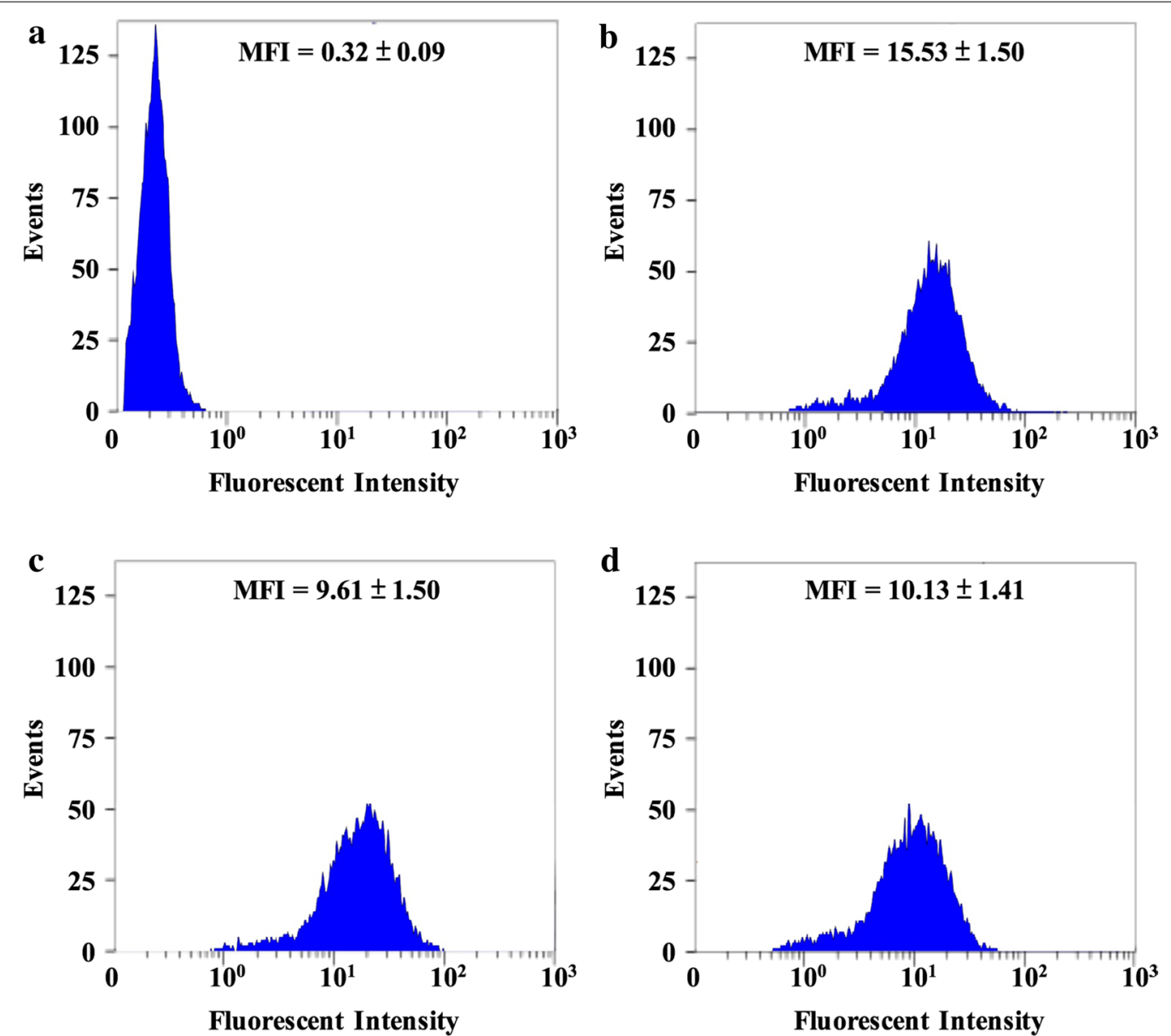

Fig. 5 Flow cytometric analysis of Lactobacillus adherence to Caco-2 cells. a Autofluorescence of Caco-2 cells. b Caco-2 cells exposed to fluorescently labeled $L$. reuteri Pg4. c Caco-2 cells exposed to fluorescently labeled $L$. reuteri pNZ3004. d Caco-2 cells exposed to fluorescently labeled $L$. reuteri pNZ-zhd101. Bacterial cells were labeled with hexidium iodide (HI) and incubated with Caco-2 cells for $2 \mathrm{~h}$. For each experiment, 10,000 Caco-2 cells were analyzed. The red fluorescence intensity of the Caco-2 cells with adherent lactobacilli was measured by flow cytometry at $620 \mathrm{~nm}$ emission wavelengths. Mean red fluorescence intensity (MFI) was calculated from two independent experiments performed in triplicate

respectively [29]. Since the intestinal environments are mildly acidic to neutral, we believe that the recombinant ZHD101 produced by L. reuteri pNZ-zhd101 can be directly delivered to the intestinal tract in an active form.

Probiotics must be able to resist to the digestion process in the gastrointestinal tract [11]. The most difficult hurdles associated with the survival of the probiotics in the gastrointestinal tract are the acidic conditions of the stomach and the bile salts in the duodenum. Gastric acid in stomach represents a primary defense mechanism against the majority of ingested microorganisms, while the bile salts in the duodenal section of the small intestine reduce the survival of bacteria because the lipids and fatty acids comprising the bacterial cell membranes are very susceptible to destruction by bile salts [30]. In a previous study, we observed that $L$. reuteri Pg4 exhibits resistance to acidic conditions and contact with bile salts in vitro [18]. In this study, all three L. reuteri Pg4 strains survived after an incubation period of $4 \mathrm{~h}$ at $\mathrm{pH}$ 3.0 (Fig. $4 \mathrm{a}$ ) or $24 \mathrm{~h}$ in MRS broth containing $0.5 \%$ ox gall (Fig. 4b). Moreover, the bacterial counts of the L. reuteri transformed strains did not differ from those of $L$. reuteri Pg4 in the acid condition or in the presence of bile salts. These results indicated that $L$. reuteri $\operatorname{Pg} 4$ strains have the potential to survive transit through the stomach and might be able to survive in the intestinal environment in where they can effectively work.

After passing through the stomach and surviving in the intestinal tract, probiotics must be able to adhere to the intestinal mucosal in order to extend their maximum probiotic effects [11]. L. reuteri is a gut symbiont that normally colonizes in the upper intestinal tract in animals and is a stable part of colonic microbiota in humans [31]. Thus $L$. reuteri strains usually show a great ability to 
adhere to mucosal cells [32-34]. A previous study demonstrated that $40 \%$ of the Lactobacillus cells randomly isolated from the digest of the ileum and caecum of broiler chickens fed with a recombinant $L$. reuteri strain possessed the capability of secreting recombinant proteins, indicating that $L$. reuteri administered orally could colonize the intestinal tract [22]. The Caco-2 cell line has been used extensively for in vitro evaluation of adhesion capacity of probiotics [20,34, 35]. In this study, Caco-2 cells that had been incubated with fluorescent-labeled L. reuteri pNZ-zhd101 for $2 \mathrm{~h}$ showed a shift along the fluorescence axis when compared with the autofluorescence expressed by Caco- 2 cells alone (Fig. 5), indicating that the $L$. reuteri cells adhered to the Caco- 2 cells. Probiotics can compete with pathogenic bacteria for the same binding sites on intestinal epithelial cells [36]. In addition, the specific enzymes secreted by recombinant probiotics that have attached themselves to intestinal epithelial cells could react directly on the substrate present in the digesta in the small intestine, where the majority of ZEN is absorbed [37]. Therefore, the ability of L. reuteri pNZ-zhd101 to adhere to intestinal mucosal cells extends its residence time in the intestinal tract and, hence allows it to achieve its maximum probiotic effects. Several exported proteins produced by $L$. reuteri have been reported to mediate the adhesion of bacterial cells to the intestinal epithelial cells [34]. The collagen-binding protein $\mathrm{Cnb}$ is one of the reported extracellular adhesion proteins produced by $L$. reuteri. Previous studies demonstrated that $\mathrm{Cnb}$ mediated $L$. reuteri adhesion to the intestinal epithelial cells and could be used as the anchor proteins for display of heterologous proteins on the cell surface of $L$. reuteri $[20,34]$. The transformed $L$. reuteri strain not only produced heterologous proteins on its cell surface but also showed higher adhesion ability than the parental $L$. reuteri strain. In order to increase the adhesion ability of $L$. reuteri pNZ-zhd101 and extend the residence time of ZHD101 in the intestinal tract, future research will focus on $\mathrm{Cnb}$ as the anchor protein for display of ZHD101 on the cell surface of $L$. reuteri Pg4.

\section{Conclusion}

We successfully cloned the $C$. rosea lactonohydrolase gene $z h d 101$ in a L. reuteri strain and demonstrated that the heterologous ZHD101 was functionally expressed by the transformed strain $L$. reuteri pNZ-zhd101. The production of heterologous ZHD101 did not affect cell growth, acid and bile salt tolerance, and had only a minor effect on the adhesion ability of L. reuteri pNZ-zhd101. Therefore, we suggested that $L$. reuteri $\mathrm{pNZ}$-zhd101 has a potential to be used as a probiotic feed additive for degradation of ZEN.

\section{Materials}

\section{Chemicals and reagents}

A stock solution of ZEN was prepared by dissolving the solid powder (Sigma-Aldrich Co. St. Louis, MO) in acetonitrile $(0.5 \mathrm{mg} / \mathrm{mL})$ and was stored in the dark at $-20{ }^{\circ} \mathrm{C}$. For high-performance liquid chromatography (HPLC) calibration or spiking purposes, the ZEN standard solutions were brought to room temperature before use and were prepared freshly by diluting the stock solutions in methanol. Acetonitrile and methanol (HPLC grade) were obtained from J. T. Baker Inc. (Phillipsburg, $\mathrm{NJ})$. Water for the HPLC mobile phase was purified successively by reverse osmosis and a Milli-Q system (Millipore, Bedford, MA). All other chemicals used were analytical reagent grade and purchased from SigmaAldrich (St. Louis, MO). All solutions prepared for HPLC were filtered through a $0.22 \mu \mathrm{m}$ nylon filter before use.

Plasmids, bacterial strains, cell line, and culture conditions The Lactobacillus expression vector pNZ3004 [38] was transformed into L. reuteri $\mathrm{Pg} 4$ to express recombinant ZHD101 proteins [18]. The Escherichia coli expression vector pET-46 Ek/LIC (Novagen, Madison, WI) was transformed into E. coli BL21 (DE3) (Novagen) to overexpress the recombinant ZHD101 protein. The pGEM$T$ Easy vector (Promega, Madison, WI) was used for all subcloning procedures and E. coli DH5 $\alpha$ (Invitrogen, Carlsbad, CA) was used as the host. Lactobacillus strains were grown in MRS broth (Difco Laboratories, Detroit, MI) at $37{ }^{\circ} \mathrm{C}$ without shaking. E. coli was cultured in Luria-Bertani (LB) broth (Difco Laboratories) at $37{ }^{\circ} \mathrm{C}$ in an orbital shaker at $250 \mathrm{rpm}$. Agar plates were prepared by adding agar $(1.5 \% \mathrm{w} / \mathrm{v})$ (Difco Laboratories) to the broth. The cancer-derived human colonic intestinal epithelial cell line Caco- 2 was used for the in vitro assay of bacterial adhesion to mammalian epithelial cells. Caco-2 cells were purchased from the Bioresource Collection and Research Center (Hsinchu, Taiwan) and were routinely grown in Dulbecco's Modified Eagle Medium (Biological Industries, Bet-Haemek, Israel) supplemented with $4 \mathrm{mM} \mathrm{L}$-glutamine (Biological Industries), $1.5 \mathrm{~g} / \mathrm{L}$ sodium bicarbonate (Biological Industries), $4.5 \mathrm{~g} / \mathrm{L}$ glucose (Sigma-Aldrich Co., St Louis, MO), $10 \mathrm{mg} / \mathrm{L}$ human transferrin (Sigma-Aldrich Co.), and 10\% fetal calf serum (Moregate Biotech, Queensland, Australia) at $37^{\circ} \mathrm{C}$ under a humidified atmosphere of $95 \%$ air and $5 \% \mathrm{CO}_{2}$.

\section{DNA isolation and manipulation}

Plasmid DNA was isolated from E. coli using the QIAprep Miniprep Kit (Qiagen Inc.) and plasmid DNA was isolated from $L$. reuteri according to the method described by O'Sullivan and Klaenhammer [39]. 
Restriction enzymes and T4 DNA ligase (New England BioLabs Inc., Beverly, MA) were used in the subcloning procedures according to the manufacturer's instructions. All other DNA manipulations were performed according to the established procedures [40]. All DNA sequences were determined by an automated sequencing service provided by Genomics Biotech Inc. (Taipei, Taiwan). Competent $E$. coli cells and $L$. reuteri Pg4 cells were prepared according to the methods described by Green et al. [40] and Hsueh et al. [35], respectively.

\section{Preparation of polyclonal antibody specific for ZHD101}

The DNA fragments encoding C. rosea ZHD101 (GenBank accession number AB076037) were synthesized chemically and cloned into the vector pUC57 (Mission Biotech Inc., Taipei, Taiwan), resulting in the plasmid pUC57-zhd101. The DNA fragments of zhd101 were amplified by PCR from pUC57-zhd101 using the oligonucleotide forward primer zhd-F1: $5^{\prime}$ GACGACGACAAGA TGCGTACTCGTAGCACTAT $3^{\prime}$ and reverse primer zhdR1: 5' GAGGAGAAGCCCGGTTAAAGGTGTTTCTGA GTAG $3^{\prime}$ (the underlined sequences in the primers are additional sequences that are compatible with the ligation-dependent cloning (LIC) site of the E. coli expression vector pET-46 Ek/LIC) and annealed to pET-46 Ek/ LIC according to the manufacturer's instructions. The resultant plasmid, designated pET-zhd101, was used to transform E. coli BL21 (DE3). Overexpression and purification of the recombinant ZHD101 were performed by standard techniques [40]. The purified ZHD101 was used to prepare polyclonal antibodies in mice as a service provided by LTK Biolab Inc. (Hsinchu, Taiwan).

\section{Heterologous expression of zhd 101 gene by L. reuteri}

To subclone the zhd101 gene into the Lactobacillus expression vector, the zhd101 gene was amplified by PCR from pET-zhd101 using the oligonucleotide forward primer zhd-F2: $5^{\prime}$ GTCGACAATGCGTACTCGTAG $3^{\prime}$ and reverse primer zhd-R2: $5^{\prime}$ CTGCAGTCAAAGGTG TTTCT $3^{\prime}$ (the underlined sequences in the primers are additional sequences that represent the restriction sites for SalI and PstI, respectively). The PCR fragments encoding ZHD101 were digested with SalI and PstI, and ligated with SalI-PstI-digested pNZ3004 to generate pNZ-zhd101. The pNZ3004 and pNZ-zhd101 plasmids were individually transformed via electroporation into L. reuteri Pg4 according to the method described by Hsueh et al. [35]. The transformants, designated L. reuteri $\mathrm{pNZ3004}$ and $L$. reuteri $\mathrm{pNZ}$-zhd101, were then confirmed not only by direct colony PCR using the zhd-F2 and zhd-R2 primer set but also by RT-PCR and western blot analyses.
For the RT-PCR analysis, $L$ b. reuteri $\mathrm{Pg} 4$, L. reuteri pNZ3004, and $L$. reuteri pNZ-zhd101 were transferred to MRS broth and incubated statically at $37{ }^{\circ} \mathrm{C}$ for $24 \mathrm{~h}$. The cells were harvested by centrifugation at $5000 \times g$ for $20 \mathrm{~min}$ at $4{ }^{\circ} \mathrm{C}$. Total RNA was extracted from the lactobacilli cells and the transcription of the $z h d 101$ gene was analyzed by RT-PCR using the zhd-F2 and zhd-R2 primer set according to the methods described by Hsueh et al. [34]. The transcription of the housekeeping 16S rRNA gene was analyzed in parallel for each sample using the $16 \mathrm{~S}-27 \mathrm{f}$ (5' AGAGTTTGATCMTGGCTCAG $3^{\prime}$ ) and 16S-1492r (5' CGGTTACCTTGTTACGACTT $3^{\prime}$ ) primer sets.

For the Western blot analysis, Lb. reuteri Pg4, L. reuteri $\mathrm{pNZ3004}$, and L. reuteri pNZ-zhd101 cells were cultivated and harvested as described above. The cell pellet was resuspended in $0.1 \mathrm{M}$ phosphate-buffered saline (PBS; $\mathrm{pH} 7.4$ ) and then sonicated for $10 \mathrm{~min}$ with an ultrasonicator (Model XL, Misonix, Farmingdale, NY). After centrifugation at $13,000 \times g$ for $20 \mathrm{~min}$ at $4{ }^{\circ} \mathrm{C}$, the intracellular extract was collected and analyzed using sodium dodecyl sulfate polyacrylamide gel electrophoresis (SDS-PAGE) according to the method described by Laemmli [41]. After electrophoresis, the proteins were transferred to a polyvinylidene difluoride (PVDF) membrane to perform the Western blot analysis according to the methods described by Huang et al. [20]. The primary and secondary antibodies used in the analysis were mouse polyclonal anti-zhd101 antibody (1:10 dilution in PBS, LTK Biolab. Inc.) and horseradish-peroxidaselinked anti-mouse IgG antibody (1:10 dilution in PBS, GE Healthcare, Piscataway, NJ), respective.

\section{Degradation of ZEN by L. reuteri strains}

Degradation of ZEN by the L. reuteri strains was performed in a $5-\mathrm{L}$ fermentor with a $2.0-\mathrm{L}$ working volume. The fermentor with MRS medium was autoclaved at $121{ }^{\circ} \mathrm{C}$ and $1.5 \mathrm{~atm}$ pressure for $15 \mathrm{~min}$. The stock solutions of ZEN and erythromycin were sterilized by filtering them through a $0.22-\mu \mathrm{m}$ nylon filter. After autoclaving, ZEN was added to the fermentor to reach a final ZEN concentration of $4.5 \mathrm{mg} / \mathrm{L}$. For the culturing of $L$. reuteri $\mathrm{pNZ} 3004$ and $L$. reuteri pNZ-zhd101, erythromycin was added to the fermentor to reach a final erythromycin concentration of $10 \mathrm{mg} / \mathrm{L}$. The fermentor was then inoculated with $1 \%(\mathrm{v} / \mathrm{v})$ of an overnight culture of L. reuteri Pg4, L. reuteri pNZ3004, or L. reuteri pNZzhd101 and incubated at $37^{\circ} \mathrm{C}$ for $14 \mathrm{~h}$ by gently stirring at $250 \mathrm{rpm}$. To maintain the $\mathrm{pH}$ of the culture medium at 7.0, sodium hydroxide $(4.0 \mathrm{~N})$ and hydrochloric acid $(3.0 \mathrm{~N})$ were added to the fermentor automatically. During the incubation period, samples were taken every hour to quantify ZEN concentration using HPLC, to determine 
viable cell count using the standard agar plate method, and to estimate the stage of the cultured cell population by measuring turbidity at $600 \mathrm{~nm}\left(\mathrm{OD}_{600}\right)$.

\section{Determination of ZEN concentration by HPLC}

The ZEN concentration in the samples was determined by HPLC according to the method described by Yi et al. [7]. The HPLC analysis was performed on a LC-20 AT delivery system (Shimadzu, Kyoto, Japan) equipped with a RF-10AXL fluorescence detector (Shimadzu), a Shimpack CLC-ODS column (Shimadzu; $250 \times 4.6 \mathrm{~mm}$ i.d., particle size $5 \mu \mathrm{g}$ ), and a SIL-10ADVP AutoSampler (Shimadzu). Before HPLC analysis for ZEN, $1 \mathrm{~mL}$ of sample was mixed with $4 \mathrm{~mL}$ of acetonitrile-water $(84: 16, \mathrm{v} / \mathrm{v}$ with ultrapure and deionized water) and then agitated on an orbital shaker at $180 \mathrm{rpm}$ for $90 \mathrm{~min}$. After centrifugation at 13,000 rpm for $5 \mathrm{~min}$, the acetonitrile phase was collected and cleaned up by using the Romer Mycosep 224 column (Romer Labs Inc., Union, MO) according to the manufacturer's instructions. After evaporating to dryness under a stream of nitrogen at $60{ }^{\circ} \mathrm{C}$, the dried residue was re-dissolved in $300 \mu \mathrm{L}$ of methanol solution (80:20, v/v with ultrapure and deionized water), filtered through a $0.45-\mu \mathrm{m}$ nylon filter to remove insoluble material, and then $20 \mu \mathrm{L}$ of the resulted solution was injected into the HPLC to quantify the ZEN concentration. The mobile phase was a methanol solution $(80: 20, \mathrm{v} / \mathrm{v}$ with ultrapure and deionized water) and was eluted at a flow rate of $0.5 \mathrm{~mL} / \mathrm{min}$. and detection was performed at excitation and emission wavelengths of 225 and $465 \mathrm{~nm}$, respectively.

\section{Acidic tolerance of the L. reuteri strains}

Acid tolerance of the $L$. reuteri strains was determined according to the method by Liu et al. [14]. A 1-mL aliquot of the overnight culture of the L. reuteri strains was centrifuged at $5000 \times g$ for $10 \mathrm{~min}$ at $4{ }^{\circ} \mathrm{C}$, the pellets were washed twice in sterile PBS (100 mM, pH 7.4) and then resuspended in $1 \mathrm{~mL}$ of the same buffer. The bacterial cells were then diluted 1/100 in $\mathrm{pH}$-adjusted MRS broth (pH 3.0) and incubated statically at $37^{\circ} \mathrm{C}$ for $4 \mathrm{~h}$. During the incubation period, a $0.1-\mathrm{mL}$ aliquot of sample was taken at 0,2 , and $4 \mathrm{~h}$ respectively to count the cell numbers using the standard agar plate method.

\section{Bile salt tolerance of the $L$. reuteri strains}

Bile salt tolerance of the $L$. reuteri strains was determined as previously described by Liu et al. [14]. Briefly, a 1-mL aliquot of overnight culture of the $L$. reuteri strains was inoculated into $100 \mathrm{~mL}$ of MRS broth containing $0.5 \%$ ox gall (Sigma), and incubated statically at $37^{\circ} \mathrm{C}$ for $24 \mathrm{~h}$. During the incubation period, a $0.1-\mathrm{mL}$ aliquot of sample was taken at 0 and $24 \mathrm{~h}$ respectively to count the cell numbers using the standard agar plate method.

\section{Adhesion abilities of the $L$. reuteri strains}

Before the adhesion assays, Caco- 2 cells were incubated with antibiotic-free medium at $37^{\circ} \mathrm{C}$ for $24 \mathrm{~h}$. After incubation, the Caco- 2 cells were removed from tissue culture flasks with an EDTA-trypsin solution, and then washed three times with $100 \mathrm{mM}$ PBS (pH 7.4). The Caco-2 cells were then resuspended in PBS containing mouse antihuman CD29 (integrin beta 1) monoclonal antibody conjugated with PerCP-eFluor 710 (diluted 1:10 in PBS; eBioscience. Inc., San Diego, CA) and incubated at room temperature for $1.5 \mathrm{~h}$. After washing three times with PBS, the immunostained Caco- 2 cells were resuspended in PBS and adjusted to a concentration of $1 \times 10^{6}$ cells/ $\mathrm{mL}$.

Lactobacillus reuteri Pg4, L. reuteri pNZ3004, and $L$. reuteri pNZ-zhd101 cells were cultivated, harvested, and resuspended in $1 \mathrm{~mL}$ of $100 \mathrm{mM}$ PBS (pH 7.4) as described above. They were then labeled with $\mathrm{HI}$ using the Live BacLight Bacterial Gram Stain Kit (Molecular Probes, Eugene, OR) according to the protocols provided by the manufacturer. Fluorescently labeled lactobacilli were added to the Caco-2 suspension to yield a final concentration of $10^{8} \mathrm{CFU} / \mathrm{mL}$ of lactobacilli and $10^{6}$ cells/ $\mathrm{mL}$ of Caco-2 cells. After incubating at $37^{\circ} \mathrm{C}$ for $2 \mathrm{~h}$, the Caco- 2 cells were harvested by centrifugation at $5000 \times g$ for $20 \mathrm{~min}$ at $4{ }^{\circ} \mathrm{C}$ and were washed three times with PBS to remove non-adherent lactobacilli. The fluorescence intensity of the Caco- 2 cells with adherent lactobacilli was measured using the Cytomics FC500 Flow Cytometry System (Beckman Coulter, Inc.) with a 488-nm argon laser and a 620-nm emission filter for $\mathrm{HI}$ detection and a 755-nm emission filter for PerCP-eFluor 710 detection. Flow cytometry was gated to include Caco-2 cells and to exclude cellular debris and non-adherent bacteria using a dot plot displaying forward scatter (FSC) vs. side scatter (SSC). Cells inside the gated area were confirmed by staining with CD29 antibody conjugated with PerCP-eFluor 710. For each analysis, 10,000 events were acquired and the flow cytometric data obtained were analyzed using CXP software (Beckman Coulter, Inc.) to produce the histograms of each individual particle sample and to calculate the mean red fluorescence intensity for each cell population. Counts were made in triplicate for each procedure.

\section{Statistical analysis}

All results were analyzed using the general linear-model procedure available with Statistical Analysis System software version 8.1 (SAS Institute Inc., Cary, NC). The 
Duncan's multiple range test [42] was used to detect differences between treatment means. Each experiment was conducted in triplicate and repeated three times.

\begin{abstract}
Abbreviations
HI: hexidium iodide; HPLC: high-performance liquid chromatography; MRS: de Man, Rogosa and Sharpe; LB: Luria-Bertani; LIC: ligation-dependent cloning; PBS: phosphate-buffered saline; PVDF: polyvinylidene difluoride; SDS-PAGE: sodium dodecyl sulfate polyacrylamide gel electrophoresis; RT-PCR: reverse transcription PCR; ZEN: zearalenone.
\end{abstract}

\section{Authors' contributions}

WCY, TCH, KCC and JRL designed the experiments, did the data analysis, and wrote the paper. All authors read and approved the final manuscript.

\section{Author details}

1 Graduate Institute of Food Science and Technology, National Taiwan University, No. 1, Sec. 4, Roosevelt Rd., Taipei 10617, Taiwan. ${ }^{2}$ Department of Animal Science and Technology, National Taiwan University, No. 1, Sec. 4, Roosevelt Rd., Taipei 10617, Taiwan. ${ }^{3}$ Institute of Biotechnology, National Taiwan University, No. 1, Sec. 4, Roosevelt Rd., Taipei 10617, Taiwan. ${ }^{4}$ Department of Medical Research, China Medical University Hospital, China Medical University, No. 91, Hsueh-Shih Road, Taichung 40402, Taiwan. ${ }^{5}$ Agricultural Biotechnology Research Center, Academia Sinica, 128 Academia Road, Section 2, Nankang, Taipei 11529, Taiwan.

\section{Acknowledgements}

Not applicable.

\section{Competing interests}

The authors declare that they have no competing interests.

\section{Availability of data and materials}

The datasets supporting the conclusions of this article are included within the article.

\section{Funding}

This research was conducted using funds partially provided by grants from the Council of Agriculture, Executive Yuan and Ministry of Science and Technology, Taiwan, Republic of China.

\section{Publisher's Note}

Springer Nature remains neutral with regard to jurisdictional claims in published maps and institutional affiliations.

Received: 4 January 2017 Accepted: 21 April 2017

Published online: 24 April 2017

\section{References}

1. Cravens RL, Goss GR, Chi F, De Boer ED, Davis SW, Hendrix SM, et al. The effects of necrotic enteritis, aflatoxin B1, and virginiamycin on growth performance, necrotic enteritis lesion scores, and mortality in young broilers. Poult Sci. 2013;92:1997-2004.

2. Rodrigues I, Naehrer K. A three-year survey on the worldwide occurrence of mycotoxins in feedstuffs and feed. Toxins. 2012;4:663-75.

3. Zinedine A, Soriano JM, Moltó JC, Mañes J. Review on the toxicity, occurrence, metabolism, detoxification, regulations and intake of zearalenone: an oestrogenic mycotoxin. Food Chem Toxicol. 2007:45:1-18.

4. Hussein HS, Brasel JM. Toxicity, metabolism, and impact of mycotoxins on humans and animals. Toxicology. 2001;167:101-34.

5. Varga J, Kocsubé S, Péteri Z, Vágvölgyi C, Tóth B. Chemical, physical and biological approaches to prevent ochratoxin induced toxicoses in humans and animals. Toxins. 2010;2:1718-50.

6. Wu Q, Jezkova A, Yuan Z, Pavlikova L, Dohnal V, Kuca K. Biological degradation of aflatoxins. Drug Metab Rev. 2009;41:1-7.
7. Yi PJ, Pai CK, Liu JR. Isolation and characterization of a Bacillus licheniformis strain capable of degrading zearalenone. World J Microbiol Biotechnol. 2011:27:1035-43.

8. Takahashi-Ando N, Kimura M, Kakeya H, Osada H, Yamaguchi I. A novel lactonohydrolase responsible for the detoxification of zearalenone: enzyme purification and gene cloning. Biochem J. 2002;365:1-6.

9. Takahashi-Ando N, Ohsato S, Shibata T, Hamamoto H, Yamaquchi I, Kimura M. Metabolism of zearalenone by genetically modified organisms expressing the detoxification gene from Clonostachys rosea. Appl Environ Microbiol. 2004;70:3239-45.

10. Higa-Nishiyama A, Takahashi-Ando N, Shimizu T, Kudo T, Yamaguchi I, Kimura M. A model transgenic cereal plant with detoxification activity for the estrogenic mycotoxin zearalenone. Transgenic Res. 2005;14:713-7.

11. Fontana L, Bermudez-Brito M, Plaza-Diaz J, Muñoz-Quezada S, Gil A. Sources, isolation, characterisation and evaluation of probiotics. Br J Nutr. 2013;109:S35-50.

12. Alonso VR, Guarner F. Linking the gut microbiota to human health. Br J Nutr. 2013;109:S21-6.

13. Steidler L. Genetically engineered probiotics. Best Pract Res Clin Gastroenterol. 2003;17:861-76.

14. Liu JR, Yu B, Liu FH, Cheng KJ, Zhao X. Expression of rumen microbial fibrolytic enzyme genes in probiotic Lactobacillus reuteri. Appl Environ Microbiol. 2005;71:6769-75

15. Cano-Garrido O, Seras-Franzoso J, García-Fruitós E. Lactic acid bacteria: reviewing the potential of a promising delivery live vector for biomedical purposes. Microb Cell Fact. 2015;14:137.

16. García-Fruitós E. Lactic acid bacteria: a promising alternative for recombinant protein production. Microb Cell Fact. 2012;11:157.

17. Molin G, Jeppsson B, Johansson ML, Ahrné S, Nobaek S, Ståhl M, et al. Numerical taxonomy of Lactobacillus spp. associated with healthy and diseased mucosa of the human intestines. J Appl Bacteriol. 1993;74:314-23.

18. Yu B, Liu JR, Chiou MY, Hsu YR, Chiou PWS. The effects of probiotic Lactobacillus reuteri $\mathrm{Pg} 4$ strain on intestinal characteristics and performance in broilers. Asian-Aust J Anim Sci. 2007;20:1243-51.

19. Liu J-R, Yu B, Zhao X, Cheng K-J. Coexpression of rumen microbial betaglucanase and xylanase genes in Lactobacillus reuteri. Appl Microbiol Biotechnol. 2007:77:117-24.

20. Huang S-J, Chen M-J, Yueh P-Y, Yu B, Zhao X, Liu J-R. Display of Fibrobacter succinogenes $\beta$-glucanase on the cell surface of Lactobacillus reuteri. J Agric Food Chem. 2011;59:1744-51.

21. Fuller R. Probiotics in man and animals. J Appl Bacteriol. 2008;66:365-78.

22. Liu JR, Lai SF, Yu B. Evaluation of an intestinal Lactobacillus reuteri strain expressing rumen fungal xylanase as a probiotic for broiler chickens fed on a wheat-based diet. Br Poult Sci. 2007;48:507-14.

23. Yu B, Liu JR, Hsiao FS, Chiou P. Evaluation of Lactobacillus reuteri Pg 4 strain expressing heterologous $\beta$-glucanase as a probiotic in poultry diets based on barley. Anim Feed Sci Technol. 2008;141:82-91.

24. Haskard C, Binnion C, Ahokas J. Factors affecting the sequestration of aflatoxin by Lactobacillus rhamnosus strain GG. Chem Biol Interact. 1999:128:39-49.

25. Peltonen K, El-Nezami H, Haskard C, Ahokas J, Salminen S. Aflatoxin B1 binding by dairy strains of lactic acid bacteria and bifidobacteria. J Dairy Sci. 2001;84:2152-6.

26. El-Nezami H, Polychronaki N, Salminen S, Mykkänen H. Binding rather than metabolism may explain the interaction of two food-grade Lactobacillus strains with zearalenone and its derivative ó-zearalenol. Appl Environ Microbiol. 2002;68:3545-9.

27. Niderkorn V, Morgavi DP, Aboab B, Lemaire M, Boudra H. Cell wall component and mycotoxin moieties involved in the binding of fumonisin B1 and B2 by lactic acid bacteria. J Appl Microbiol. 2009;106:977-85.

28. Merchant HA, McConnell EL, Liu F, Ramaswamy C, Kulkarni RP, Basit AW, et al. Assessment of gastrointestinal pH, fluid and lymphoid tissue in the guinea pig, rabbit and pig, and implications for their use in drug development. Eur J Pharm Sci. 2011;42:3-10.

29. Mabelebele M, Alabi OJ, Ng JW, Norris D, Ginindza MM. Comparison of gastrointestinal tracts and pH values of digestive organs of Ross 308 broiler and indigenous venda chickens fed the same diet. Asian J Anim Vet Adv. 2014;9:71-6.

30. Jin LZ, Ho YW, Abdullah N, Jalaludin S. Acid and bile tolerance of Lactobacillus isolated from chicken intestine. Lett Appl Microbiol. 1998;27:183-5. 
31. Su MS-W, Oh PL, Walter J, Gänzle MG. Intestinal origin of sourdough Lactobacillus reuteri isolates as revealed by phylogenetic, genetic, and physiological analysis. Appl Environ Microbiol. 2012;78:6777-80.

32. Roos S, Jonsson H. A high-molecular-mass cell-surface protein from Lactobacillus reuteri 1063 adheres to mucus components. Microbiology. 2002;148:433-42.

33. Miyoshi Y, Okada S, Uchimura T, Satoh E. A mucus adhesion promoting protein, MapA, mediates the adhesion of Lactobacillus reuteri to Caco-2 human intestinal epithelial cells. Biosci Biotechnol Biochem. 2006;70:1622-8.

34. Hsueh H-Y, Yueh P-Y, Yu B, Zhao X, Liu J-R. Expression of Lactobacillus reuteri Pg4 collagen-binding protein gene in Lactobacillus casei ATCC 393 increases its adhesion ability to Caco-2 cells. J Agric Food Chem. 2010;58:12182-91.

35. Hsueh H-Y, Yu B, Liu C-T, Liu J-R. Increase of the adhesion ability and display of a rumen fungal xylanase on the cell surface of Lactobacillus casei by using a listerial cell-wall-anchoring protein. J Sci Food Agric. 2014;94:576-84.

36. Vélez MP, De Keersmaecker SCJ, Vanderleyden J. Adherence factors of Lactobacillus in the human gastrointestinal tract. FEMS Microbiol Lett. 2007;276:140-8
37. Zielonka Ł, Waśkiewicz A, Beszterda M, Kostecki M, Dąbrowski M, Obremski $\mathrm{K}$, et al. Zearalenone in the intestinal tissues of immature gilts exposed per os to mycotoxins. Toxins. 2015;7:3210-23.

38. van Rooijen RJR, Gasson MJM, de Vos WMW. Characterization of the Lactococcus lactis lactose operon promoter: contribution of flanking sequences and LacR repressor to promoter activity. J Bacteriol. 1992;174:2273-80.

39. Osullivan DJ, Klaenhammer TR. Rapid mini-prep isolation of high-quality plasmid DNA from Lactococcus and Lactobacillus spp. Appl Environ Microbiol. 1993;59:2730-3.

40. Green MR, Sambrook J. Molecular cloning: a laboratory manual. 4th ed. Cold Spring Harbor: Cold Spring Harbor Laboratory Press; 2012.

41. Laemmli UK. Cleavage of structural proteins during the assembly of the head of bacteriophage T4. Nature. 1970;227:680-5.

42. Montgomery DC. Design and analysis of experiments. 8th ed. New York: John Wiley and Sons; 2012.

\section{Submit your next manuscript to BioMed Central and we will help you at every step:}

- We accept pre-submission inquiries

- Our selector tool helps you to find the most relevant journal

- We provide round the clock customer support

- Convenient online submission

- Thorough peer review

- Inclusion in PubMed and all major indexing services

- Maximum visibility for your research

Submit your manuscript at www.biomedcentral.com/submit 